\title{
Cancer strategy needed but political will lacking
}

Amidst criticism that Canada has done enough to combat rising cancer rates, Canada's Public Health minister has cautiously endorsed the concept of a national cancer control strategy, suggesting the new Public Health Agency will coordinate it.

Dr. Carolyn Bennett said there's a need for a national strategy on cancer. The question is who should direct the strategy and how should it work.

The Minister of State for Public Health said the federal government must lead the strategy forward, but added that health issues such as cancer, infectious diseases, epidemics and heart disease are interconnected and require a coherent approach. Bennett suggests the new federal public health agency should coordinate strategies for all health initiatives.

The Canadian Cancer Socio ety welcomes Bennett's interest o̊ in the cancer strategy and in a - balanced approach to disease

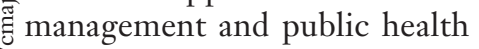
ô systems.

But the policymakers in$\ddot{\ddot{H}}$ volved with a fledgling cancer ڤ strategy do not want their ideas

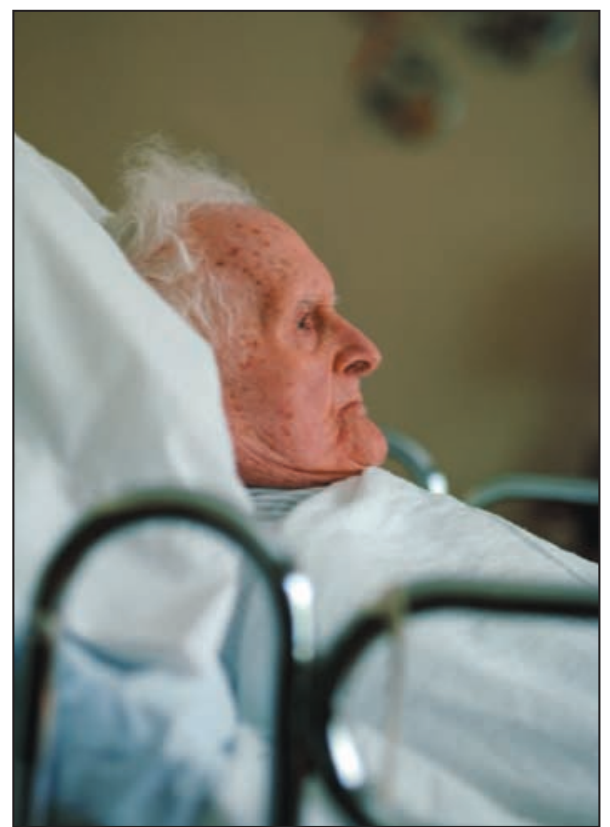

As the population ages, the incidence of cancer is expected to rise $60 \%$. to be diluted or progress to date to be lost. "Making progress in the fight against cancer requires both a much wider investment of resources than a public health agency alone provides," says Cancer Society CEO Dr. Barbara Whylie. "We are looking for support across different government agencies, not just Health.”

But there is no evidence that a coordinated approach is a priority on the federal agenda. The struggling 5-year-old Canadian Strategy for Cancer Control - a consortium of 4 national groups, including Health Canada - receives $\$ 1.15$ million in annual funding (Health Canada provides $\$ 900$ 000). By comparison, the national AIDS strategy receives $\$ 42$ million annually.

Given the rising incidence of cancer, the need for a national, coordinated strategy will soon be urgent, says Whylie. By 2010 the society expects cancer to surpass heart disease as the leading killer of Canadians largely because of the aging population. This year an estimated 145500 Canadians will be diagnosed with cancer; 68300 will die. The number of new cancer cases diagnosed each year will jump by $60 \%$ over the next 2 decades.

The financial burden on the health care system will be enormous. Cancer cost the national economy $\$ 14.3$ billion in 1998 , including $\$ 2.5$ billion in direct costs for treatment, care and rehabilitation, and $\$ 11.8$ billion in indirect costs, principally lost productivity.

The cancer consortium, including the society, the Canadian Association of Provincial Cancer Agencies, Health Canada and the National Cancer Institute of Canada (NCIC), launched the strategy in 1999. Its goals are to reduce the risk of developing cancer and dying of cancer, and to improve cancer care, including screening, treatment, quality of life and access to services.
The cancer strategy's six working groups (standards, guidelines, human resource planning, prevention, strategic research and rebalance focus) have formulated priorities, which the group's council is reviewing.

Despite this progress, those involved are discouraged by what they call a lack of political leadership.

" $[\mathrm{We}]$ are frustrated and disappointed about the low level of engagement [with the strategy] and the issues in cancer control," says Dr. Andrew Padmos, the chair of the Strategy's Human Resources-Action Group and Commissioner of Cancer Care Nova Scotia.

Responding to Bennett's position that the new health agency oversee the strategey, Padmos says he is concerned that "stateof-the-art" programs and initiatives the consortium is developing might never become reality if the strategic direction changes. "It would be a shame to lose that momentum," he says. "It is that momentum that would enable us to act in a coordinated fashion to address a national catastrophic problem."

Previously, Liberal Senator Sharon Carstairs was the only federal figure to speak out in favour of a strategy that would include national standards and treatment guidelines.

"I am calling for the federal government to bring to the table the players - provincial, territorial and regional - so that the dialogue can begin," she told the Senate in March.

On May 17, Bennett announced that the new public health agency will be run out of Winnipeg and Ottawa, working with 6 collaborating centres across the country. Dr. Frank Plummer, currently director general of Health Canada's Centre for Disease Prevention and Control, will serve as acting chief public health officer until a permanent officer is named. Pauline Comeau, Ottawa 